
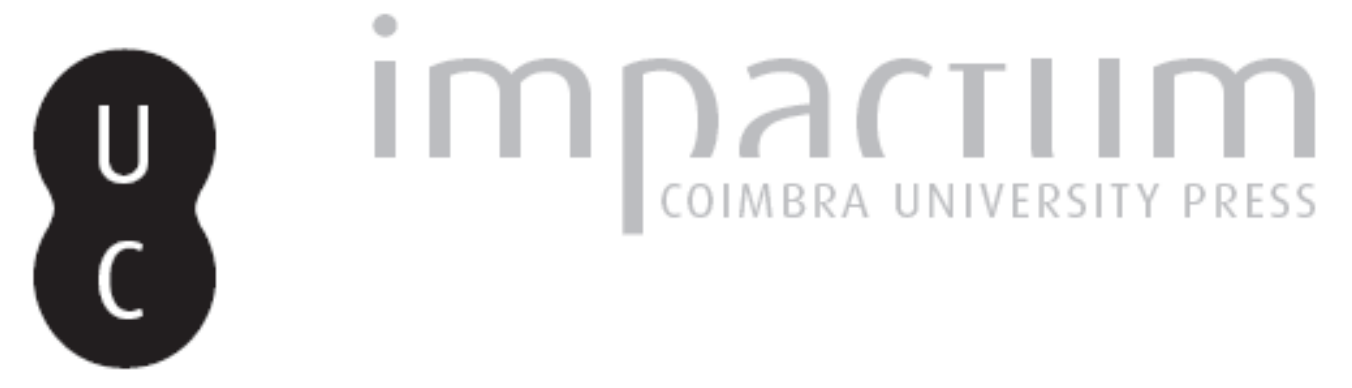

\title{
A necrópole romana da Lage de Ouro: novos elementos
}

Autor(es): $\quad$ Frade, Helena; Caetano, José Carlos

Publicado por: Imprensa da Universidade de Coimbra

URL persistente:

URI:http://hdl.handle.net/10316.2/45526

DOI:

DOI:https://dx.doi.org/10.14195/1647-8657_30_4

Accessed : $\quad$ 26-Apr-2023 02:31:52

A navegação consulta e descarregamento dos títulos inseridos nas Bibliotecas Digitais UC Digitalis, UC Pombalina e UC Impactum, pressupõem a aceitação plena e sem reservas dos Termos e Condições de Uso destas Bibliotecas Digitais, disponíveis em https://digitalis.uc.pt/pt-pt/termos.

Conforme exposto nos referidos Termos e Condições de Uso, o descarregamento de títulos de acesso restrito requer uma licença válida de autorização devendo o utilizador aceder ao(s) documento(s) a partir de um endereço de IP da instituição detentora da supramencionada licença.

Ao utilizador é apenas permitido o descarregamento para uso pessoal, pelo que o emprego do(s) título(s) descarregado(s) para outro fim, designadamente comercial, carece de autorização do respetivo autor ou editor da obra.

Na medida em que todas as obras da UC Digitalis se encontram protegidas pelo Código do Direito de Autor e Direitos Conexos e demais legislação aplicável, toda a cópia, parcial ou total, deste documento, nos casos em que é legalmente admitida, deverá conter ou fazer-se acompanhar por este aviso. 
FACULDADE DE LETRAS

INSTITUTO DE ARQUEOLOGIA

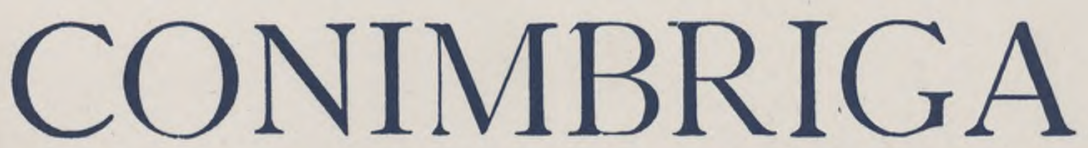

VOLUME XXX

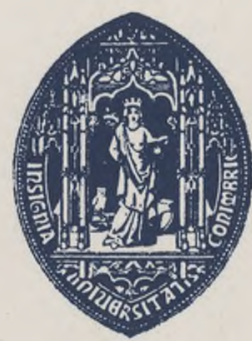

UNIVERSIDADE DE COIMBRA 


\section{A NECRÓPOLE ROMANA DA LAGE DO OURO: NOVOS ELEMENTOS \\ «Conimbriga» XXX (1991), p. 39-57}

RESUMO: Dão-se a conhecer os resultados das escavações efectuadas na necrópole romana da Lage do Ouro (Crato), no ano de 1988.

Trata-se de uma necrópole cujo período de utilização vai desde o séc. I d. C. até aos sécs. IV/V. A análise dos enterramentos escavados permite concluir que o ritual de incineração foi aqui usado até ao séc. IV, a par com o de inumação. Com base nos conjuntos de oferendas fúnebres é também possível alargar a cronologia das cerâmicas comuns desta região.

RÉSumÉ: On présente le résultat des fouilles de 1988 dans la nécropole romaine de Lage do Ouro (Crato).

Cette nécropole a été utilisée dès le $1^{\text {er }}$ siècle ap. J. C. jusqu'aux IV/Vème siècles. On peut dire que l'incinération et l'inhumation y existent au IIİ̀me et au IVème siècles. Cette fouille a aussi permis de préciser la chronologie des céramiques communes. 
(Página deixada propositadamente em branco) 


\section{A NECROPOLE ROMANA DA LAGE DO OURO: NOVOS ELEMENTOS *}

Após cinco anos de interrupção, foram retomados em 1988(1) os trabalhos de escavação na necrópole romana da Lage do Ouro( $\left.{ }^{2}\right)$.

Em 1985, nas las Jornadas de Arqueologia do Nordeste Alentejano, tentámos fazer o balanço do que tinham sido as duas primeiras campanhas de escavações (1982 e 1983). Fizemos, com as sepulturas até então encontradas, 7 grupos principais e 6 variantes. Utilizámos como características definidoras de cada grupo a forma, o tamanho, a presença ou ausência de espólio orgânico (cinzas, ossos e carvões) e o modo de cobertura das sepulturas (Frade e Caetano 1985).

Os bons resultados obtidos na campanha de 1988 permitiram-nos ter uma visão mais correcta e mais alargada sobre estes problemas anteriormente enunciados.

Assim, nesta campanha foram escavados 10 quadrados (Fig. 1) onde se identificaram 39 sepulturas $\left({ }^{3}\right)$. Com excepção da 137.2, todas as

* Este trabalho foi originalmente apresentado numa comunicação nas II Jornadas de Arqueologia do Nordeste Alentejano, que se realizaram em Monforte em 1989.

( ${ }^{x}$ Esta campanha só se tornou possível graças à compreensão do Prof. José Coelho Cartas Pimentel, proprietário do terreno, e ao apoio do Sr. António José Leitão, Presidente da Câmara Municipal do Crato. Cabe também aqui um agradecimento especial aos Drs. Adília Alarcão, José Beleza Moreira e Maria Helena Simões por todo o apoio prestado, e ao Dr. José Luís Madeira pelo seu trabalho com os desenhos desta estação.

${ }^{2}$ ) Freguesia de Aldeia da Mata, concelho de Crato. Coordenadas Gauss N 367 615, da C.M.P. 1/ 25000, folha nQ 346.

(3) Os quadrados são identificados com letras no sentido N/S, e com números no sentido W/E. As sepulturas são numeradas, a partir de 1 , pela sua ordem de aparecimento dentro de cada quadrado. As peças do espólio são também numeradas pela sua ordem de aparecimento dentro de cada sepultura. 
sepulturas são enterramentos feitos em covas abertas no saibro (Figs. 2 e 3).

Apenas 7 sepulturas apresentavam sinais de violação, pelo que se afigura útil fazer a descrição sumária de cada estrutura tumular. Os elementos referidos são: dimensões, em centímetros (comprimento $\mathrm{x}$ largura x profundidade); orientação; forma; espólio e observações.

\section{G 37.1}

$192 \times 88 \times 40$.

N/S.

Subrectangular.

Sem espólio orgânico.

5 cerâmicas, 8 pregos e 3 objectos em ferro.

Cerâmica na parte sul da sepultura.

\section{G 37.2}

$205 \times 94 \times 45$.

$\mathrm{N} / \mathrm{S}$.

Subrectangular.

Sem espólio orgânico.

7 cerâmicas, 25 pregos, 13 preguetas, 1 objecto em ferro e 1 vidro.

Cerâmica na parte sul da sepultura. Os pregos definiam uma caixa.

\section{G 37.3}

$161 \times 45 \times 42$.

$\mathrm{N} / \mathrm{S}$.

Rectangular.

Sem espólio orgânico.

3 cerâmicas, 1 moeda.

O fundo da sepultura estava forrado com 2 tégulas, a sul das quais estava o espólio.

\section{G 39.1}

$253 \times 90 \times 36$.

WNW/ESE.

Subrectangular.

Sem espólio orgânico.

3 cerâmicas.

Espólio encostado às paredes da sepultura. 


\section{G 39.2}

$195 \times 95 \times 50$.

WNW/ESE.

Subrectangular.

Sem espolio orgânico.

5 cerâmicas.

Espólio encostado às paredes da sepultura.

\section{G 39.3}

$200 \times 52 \times 45$.

WNW/ESE.

Subrectangular.

Sem espólio orgânico.

3 cerâmicas.

Espólio encostado às paredes da sepultura.

\section{H 37.1}

$106 \times 69 \times 20$.

NNE/SSW.

Oval.

Ossos e carvões na parte norte da sepultura, por cima do espólio.

1 cerâmica.

\section{H 37.2}

$88 \times 56 \times 33$.

NNE/SSW.

Rectangular.

Ossos, cinzas e carvões enchendo a cova.

2 pregos, 1 moeda e 1 vidro.

\section{H 37.3}

$88 \times 65 \times 21$.

N/S.

Oval.

Com cinzas, ossos e carvões.

1 cerâmica, 2 pregos e 1 pregueta.

A espessura das cinzas $(25 \mathrm{~cm})$ excedia a profundidade da cova, formando um montículo.

Conimbriga, 30 (1991), 39-57 


\section{1}

$206 \times 74 \times 28$.

NNE/SSW,

Rectangular.

A Sul da sepultura e fora dela, havia um amontoado de cinzas.

3 cerâmicas, 18 pregos.

\section{2}

Amontoado de cinzas, de forma circular, com cerca de $60 \mathrm{~cm}$ de diâmetro e $10 \mathrm{~cm}$ de espessura, depositado sobre a rocha.

2 cerâmicas, 1 prego e 1 moeda.

\section{3}

$70 \times 58 \times 20$.

$\mathrm{W} / \mathrm{E}$.

Rectangular.

Cinzas, ossos e carvões enchendo a cova.

\section{4}

$101 \times 60 \times 34$.

NNE/SSW.

Subrectangular.

Cinzas, ossos e carvões enchendo a cova.

5 pregos, 1 vidro.

Possivelmente violada.

\section{5}

$164 \times 74 \times 20$.

N/S.

Oval.

Ossos calcinados na parte sul da sepultura.

1 prego.

\section{7}

$98 \times 50 \times 15$.

NNE/SSW.

Irregular.

Cinzas, ossos e carvões.

1 cerâmica, 1 vidro.

Conimbriga, 30 (1991), 39-57 
As cinzas, com cerca de $25 \mathrm{~cm}$ de espessura, enchiam a cova e formavam um montículo por cima dela.

0 espólio estava envolvido pelas cinzas, na parte superior do montículo.

\section{8}

$200 \times 125 \times 43$.

NNE/SSW.

Oval.

Sem espolio orgánico.

1 cerámica, encostada à parede $\mathrm{W}$.

\section{L37.1}

$83 \times 78 \times 12$.

$\mathrm{W} / \mathrm{E}$.

Quadrangular. •

Cinzas e ossos enchendo a sepultura.

4 cerâmicas, 10 pregos, 2 preguetas.

Pela presença de um brinquedo, em cerâmica, será possivelmente a sepultura de uma criança. Espólio na parte superior do montículo formado pelas cinzas.

\section{L37.2}

$85 \times 63 \times 12$.

$\mathrm{N} / \mathrm{S}$.

Rectangular.

Cinzas, ossos e carvões enchendo a cova.

6 cerâmicas, 2 pregos.

As cinzas formavam um montículo por cima da sepultura. Na sua parte superior estava o espólio.

\section{L37.3}

$224 \times 81 \times 48$.

$\mathrm{N} / \mathrm{S}$.

Rectangular.

Com algumas cinzas, espalhadas pela sepultura.

6 cerâmicas, 16 pregos, 42 preguetas, 2 objectos de ferro, 1 moeda e 1 vidro.

Espólio concentrado na parte norte da sepultura. Quase no fundo existia um imbrice que cobria algumas peças.

\section{37.4}

246 X $100 \times 50$.

$\mathrm{N} / \mathrm{S}$.

Rectangular. 
Carvões espalhados pela sepultura.

47 pregos, 120 preguetas, 1 anel em prata, 2 fragmentos de cobre, de peça indeterminada.

Sepultura violada. Terá tido uma tampa constituída por lajes de granito, de que restavam as dos topos norte e sul. Alguns fragmentos cerâmicos, quase inidentificáveis, estavam espalhados pela parte superior da sepultura.

\section{37.5}

$187 \times 68 \times 25$.

N/S.

Sem espólio orgânico.

5 cerâmicas, 2 pregos, 43 preguetas, 1 fragmento de ferro de peça indeterminada, 1 moeda.

Sepultura coberta por um telhado composto por quatro tégulas dispostas perpendicularmente ao eixo da sepultura e não a cobrindo totalmente.

\section{38.1}

$173 \times 95 \times 45$.

N/S.

Subrectangular.

Com alguns carvões, poucos, espalhados na sepultura.

7 pregos, 1 pulseira em vidro.

Sepultura violada, com alguns fragmentos cerâmicos misturados na terra.

\section{38.2}

$192 \times 121$ X 17.

WNW/ESE.

Oval.

Com ossos calcinados na parte sul.

3 cerâmicas, 1 objecto em ferro, 2 pulseiras em cobre.

\section{38.3}

$147 \times 110 \times 25$

NW/SE.

Irregular.

Sem espólio orgânico.

5 cerâmicas, 6 pregos, 47 preguetas, 12 objectos em ferro.

\section{38.4}

$195 \times 71 \times 75$.

Rectangular. 
Sem espólio orgânico.

5 cerâmicas, 22 pregos, 1 objecto em ferro, 1 vidro.

Os pregos desta sepultura definiam uma caixa.

\section{38.5}

$214 \times 78 \times 48$.

$\mathrm{N} / \mathrm{S}$.

Rectangular.

Com alguns carvões entre as peças cerâmicas.

6 cerâmicas, 24 pregos, 207 preguetas, 7 objectos de ferro, 1 moeda, 1 vidro.

\section{39.1}

$206 \times 94 \times 36$

$\mathrm{N} / \mathrm{S}$.

Rectangular.

Com cinzas.

1 cerâmica, 12 pregos, 131 preguetas, 2 objectos em ferro.

As cinzas estavam numa pequena cova de forma circular, com cerca de $30 \mathrm{~cm}$ de diâmetro, situada a sul da sepultura.

\section{39.2}

$144 \times 65 \times 30$.

$\mathrm{N} / \mathrm{S}$.

Subrectangular.

Sem espólio orgânico.

3 cerâmicas, 3 pregos.

Junto à parede norte existia um imbrice incompleto.

\section{39.3}

$218 \times 93 \times 30$

$\mathrm{N} / \mathrm{S}$.

Subrectangular.

Sem espólio orgânico.

5 cerâmicas, 7 pregos.

\section{L39.4}

$126 \times 65 \times 37$.

$\mathrm{N} / \mathrm{S}$.

Irregular. 
Sem espólio orgânico.

2 cerâmicas.

\section{29.1}

$160 \times 67 \times 77$.

$\mathrm{N} / \mathrm{S}$.

Rectangular.

Sem espólio orgânico ou qualquer outro tipo de espólio.

Sepultura identificada pela presença de um imbrice inteiro na sua parte norte e à superfície. Possivelmente terá sido violada.

\section{29.2}

$225 \times 95 \times 55$.

NNE/SSW.

Subrectangular.

Alguns carvões junto à parede sul.

6 cerâmicas, 17 pregos, 158 preguetas, 4 objectos de ferro, 1 moeda.

\section{30.1}

$190 \times 94 \times 20$.

$\mathrm{N} / \mathrm{S}$.

Rectangular.

Sem espólio orgânico.

6 cerâmicas, 24 pregos, 1 moeda, 1 vidro.

A sepultura tinha uma grande laje de pedra que lhe servia de tampa. Esta laje foi mexida, possivelmente por um tractor, e ficou na vertical dentro da sepultura, dividindo-a ao meio no sentido N/S. A metade este da sepultura ficou intacta enquanto que a metade oeste foi destruída.

\section{30.2}

$230 \times 94 \times 20$.

$\mathrm{N} / \mathrm{S}$.

Rectangular.

Sem espólio orgânico.

3 cerâmicas, 6 pregos.

Uma das cerâmicas estava colocada sobre um imbrice incompleto na parte sul da sepultura.

\section{30.3}

$187 \times 80 \times 25$

$\mathrm{N} / \mathrm{S}$.

\section{Conimbriga, 30 (1991), 39-57}


Irregular.

Sem espolio orgânico.

4 cerâmicas, fragmentos de ferro de peça indeterminada.

\section{30.4}

$175 \times 62 \times 40$.

$\mathrm{N} / \mathrm{S}$.

Subrectangular.

Sem espólio orgânico.

3 cerâmicas, 1 objecto em ferro.

O fundo da sepultura tinha duas tégulas, dispostas no sentido do comprimento, sobre as quais se encontrava o espólio. Na parte sul cobrindo uma bilha, havia também uma tégula.

\section{30.5}

$197 \times 70 \times 55$.

N/S.

Sem espólio orgânico.

4 cerâmicas, 8 pregos.

A tampa desta sepultura era um telhado formado por quatro tégulas, dispostas perpendicularmente ao eixo da sepultura, com quatro imbrices cobrindo as juntas. A sul, uma outra tégula cobria o telhado. Dentro da sepultura e encostada à parede oeste, outra tégula, na vertical, servia de apoio a parte do telhado.

\section{N 30.1}

$200 \times 85 \times 45$.

$\mathrm{N} / \mathrm{S}$.

Rectangular.

Carvões junto das paredes norte e sul.

5 cerâmicas, 1 prego, 1 moeda.

\section{N 30.2}

Cova assinalada por uma coloração diferente do terreno, tinha uma forma bastante irregular e não forneceu qualquer espólio.

Os cinzeiros escavados nesta campanha de 1988 não apresentam grandes diferenças morfológicas dos encontrados em anos anteriores. Um deles, I 37.2, terá sido uma simples deposição de cinzas e cerâmica sobre a rocha de base. No entanto, a pouca espessura de terra que o cobria e o remeximento provocado pelos trabalhos agrícolas, originaram a 
fractura e dispersão dos materiais, não permitindo uma leitura correcta do enterramento e da disposição do espólio.

Noutros cinzeiros (H 37.2; 137.7; L 37.1 e L 37.2), verificou-se que a espessura das cinzas excedia a profundidade da cova, formando assim um pequeno montículo sobre ela. Nestes casos o espólio funerário foi colocado na parte superior das cinzas, mas envolvido por elas (Est. 1).

Nos restantes cinzeiros (H 37.3; 137.3 e 137.4), o espólio estava no meio das cinzas, que enchiam completamente a cova mas não a excediam.

A sepultura L 37.3 tinha vestígios muito ténues de cinzas misturadas com a terra que a enchia. Cinzas apareceram também a Sul da sepultura 137.1, num amontoado de pequena espessura, e a Sul da L 39.1, dentro duma pequena cova circular. Estas cinzas não foram numeradas como sepulturas. Foram consideradas como fazendo parte dos enterramentos que lhes estavam juntos porque, no caso da I 37.1, as cinzas estavam junto do bordo sul da sepultura, prolongando-a. Na L39.1, a cova com as cinzas era de muito pequenas dimensões e não tinha espólio.

Embora sem cinzas, as sepulturas H 37.1; I 37.5 e L 38.2, todas de forma oval, tinham ossos calcinados dentro das covas. Não eram muitos e estavam localizados junto ao espólio.

Algumas outras sepulturas tinham pequenos pedaços de carvão misturados com a terra. A sua quantidade não nos permite afirmar que sejam vestígios de incineração.

As restantes sepulturas são quase todas de forma rectangular e profundas, sem vestígios de inumações ou de incinerações. Foram elas que forneceram os maiores e mais variados conjuntos de oferendas, normalmente colocadas na parte sul da sepultura ou encostadas às paredes.

Refiram-se, em primeiro lugar, as três sepulturas do quadrado G 39. De grandes dimensões e profundas, destacam-se por estarem orientadas WNW/ESE, enquanto as restantes apresentam uma orientação N/S, com poucas variações de amplitude. Além disso, o seu espólio era exclusivamente cerâmico, encostado às paredes da cova, e não encontrámos vestígios de qualquer tipo de cobertura ou de revestimento interno.

As restantes revelaram algumas particularidades que as individualizam, levando à suposição da existência de diferentes rituais funerários, perpetuados em diversos modos de construção e arranjo dos túmulos.

Assim, podemos falar em sepulturas que tiveram caixas de madeira dentro das covas; sepulturas com o fundo revestido por tégulas (Est. 2) e sepulturas com coberturas de lajes de pedra, de tégulas e de tégulas e de imbrices, formando telhado (Est. 3). 
Todas as sepulturas tinham espolio, com excepção de duas pertencentes ao grupo das que supomos violadas, e de um cinzeiro.

As peças inventariadas nesta campanha são cerca de 1250, distribuídas do seguinte modo: 112 cerâmicas, 6 lucernas, 8 vidros, 10 moedas, 37 objectos em ferro, 276 pregos, 791 pregueias e 4 objectos de adorno.

As cerâmicas, na sua maioria comuns, têm bastantes semelhanças nas pastas e nas formas com as peças exumadas das necrópoles de Eivas. Por isso, foram classificadas utilizando as denominações propostas por Jeannette Nolen (1985: 35-139).

Nas formas têm predominância os púcaros(37), seguidos das bilhas (32), dos pratos (22), das taças, malgas e tigelas (16) e dos potes (4). Merece ainda referência a peça L 37.1:10, um pequeno brinquedo com a forma de um potinho, que não foi enquadrado em nenhuma destas categorias.

A associação mais frequente de formas, em cada sepultura, é bilhaprato-púcaro, que aparece em 11 das 37 sepulturas com espólio. Por vezes, o prato é substituído por uma taça ou afim (em 6 sepulturas). A associação bilha-púcaro ocorre em 7 casos.

Os pequenos púcaros de duas asas, de pastas finas, aos quais normalmente se atribuem datações até aos meados do séc. Ill (Nolen 1985: 67), aparecem aqui associados a materiais mais tardios, o que pressupõe a continuação da forma pelo menos até aos inícios do séc. IV.

As lucernas, numa primeira análise feita antes da limpeza, parecem ser de fabricos regionais comuns nos sécs. III e IV. Excepção poderá ser a lucerna aparecida no cinzeiro 137.7, que parece ser mais antiga, datando da 2- metade do séc. II.

Nesta campanha foi encontrada uma lucerna com a marca GES. Esta marca já se encontra representada nesta necrópole por uma outra lucerna proveniente de uma sepultura escavada em 1982. Ambas têm marcas esgrafitadas, com palma. A lucerna encontrada em 1982 representa Minerva com capacete e escudo, e é de difícil integração cronológica. Parece ser um produto que terá aproveitado um modelo de disco, orla e bico mais antigo. A encontrada este ano na sepultura L 39.3 (Est. 4), e cujo disco tem uma Vitória alada, integra-se no tipo Deneauve VIII B, normalmente apontado como sendo característico do séc. III (Belchior 1969: 62).

O fabrico destas lucernas tem sido localizado em Mérida, ou nas suas proximidades (Balil 1966: 122). Em Portugal estes produtos 
eram conhecidos, até agora, em Tróia, Alcácer do Sal, Barrosinha e $\operatorname{Balsa}\left({ }^{4}\right)$.

Sobre os vidros, pouco poderemos adiantar, uma vez que o seu estado de fragmentação obrigou a que fossem impregnados, para posterior tratamento laboratorial. Seguramente, apenas podemos dizer que a peça 137.7:2 é uma taça de vidro incolor. No entanto, muitos fragmentos parecem ser semelhantes às peças publicadas por Maria Helena Simões (1985: 123-125), provenientes desta mesma necrópole, e que acentuam a sua ocupação tardia.

As moedas encontradas não permitiam a sua identificação imediata, pelo que esta só será possível após a limpeza a que neste momento se procede. Em campanhas anteriores, as moedas encontradas pertencem a cunhagens dos sés. II e III — Faustina, Júlia Mameia e Maximino $\left(^{5}\right)$.

É notável a quantidade e a qualidade dos objectos em ferro encontrados nesta campanha. Distribuídos por 13 sepulturas, os conjuntos mais numerosos apareceram na L 38.3 (com 12 peças) e na L 38.5 (com 7 peças - Est. 5).

Representam, na sua maioria, instrumentos ligados a diversas profissões: pedreiro, carpinteiro, lenhador, agricultor. São em tudo semelhantes às ferramentas publicadas por Sálete da Ponte, provenientes das necrópoles de Eivas (1986:99-129). A tenaz da L 38.5 parece ter paralelo numa outra encontrada em Vale do Junco (Carvalho 1987: 65).

Os pregos pertenciam, em grande parte, às caixas de madeira que terão existido nas sepulturas. Foram encontrados junto às paredes e aos cantos, de bico para cima ou cruzados (Est. 6). Alguns têm mesmo os bicos revirados, devido a terem sido martelados. Nos cinzeiros, os pregos que aí apareceram poderiam ter pertencido à padiola onde foi transportado o corpo e que foi queimada com ele (137.2; H 37.2 ou L 37.2). Noutras sepulturas, pela sua pouca quantidade, poderão ter um carácter votivo. Veja-se, por exemplo, que na L 37.5, na L 39.2 e na N 30.1 havia somente um prego junto ao espólio cerâmico.

As preguetas estão distribuídas por 10 sepulturas, em quantidades que vão de 1 na H 37.7 a 207 na L 38.5. De um modo geral, apareciamnos à volta das peças cerâmicas ou amontoadas como se tivessem sido colocadas dentro de uma bolsa.

(4) Ver mapa de distribuição em Cabral 1974-1977: 348.

$\left({ }^{5}\right)$ Agradecemos à Dr-. Isabel Pereira, do Museu Municipal Dr. Santos Rocha, da Figueira da Foz, a classificação destas moedas. 
Esta disposição das preguetas não é desconhecida em necrópoles romanas já escavadas, como a necrópole de Sétif, utilizada desde o séc. II ao IV. Nesta necrópole, nas sepulturas de inumação as preguetas apareciam alinhadas, formando bandas, junto aos tornozelos ou ao crânio dos esqueletos, enquanto que nas de incineração estavam junto às peças cerâmicas (Guéry 1985: 139 e 243).

Nos objectos de adorno englobámos uma pulseira em vidro, duas pulseiras em cobre e um anel, em prata, de mesa oval e pedra gravada.

As sepulturas até agora encontradas pertencem ao período de utilização da necrópole que parece situar-se entre os sécs. II e IV. Convém aqui lembrar a existência de duas inscrições funerárias, provenientes deste local, atribuídas ao séc. I (IRCP 624 e 628). No entanto, não encontrámos, até agora, os enterramentos desse século.

$\mathrm{O}$ ritual de incineração praticava-se já em Roma nos sécs. VII e VI a.C. (Van Doorselaer 1967: 29), e o seu uso manteve-se, a par com o da inumação, até ao fim do Império. Segundo A. Bellino (1900: 25), "entre os romanos o costume da cremação durou até ao tempo do imperador Graciano, (ano de 367), que o prohibiu de vez". Deve ter, porém, continuado a ser utilizado, uma vez que foi de novo proibido, por ser considerado uma prática pagã, por Carlos Magno, em 785 (Van Doorselaer 1969: 49).

Tem existido a ideia generalizada de que o ritual de incineração foi utilizado só até ao fim dos dois primeiros séculos da nossa era. Talvez por isso De Klijn refira um enterramento de finais do séc. II, dizendo ser um exemplo bastante tardio de incineração (1987: 141-142). Porém, são múltiplas as necrópoles em que a incineração era praticada no séc. Ili e no séc. IV. Em Sétif, é utilizada desde o séc. I até à 2- metade do séc. III (Guéry 1985: 133-233). Para a Gália Setentrional, Van Doorselaer fornece dados estatísticos de necrópoles com incinerações datadas depois de 256 d. C. (1967: 30 e 51). Na necrópole de La Calade existem incinerações datadas do séc. III (Bérard 1961:156). Na publicação de La Torrecilla, são referidas algumas necrópoles com incinerações do séc. III. Os autores explicam a utilização deste rito em épocas tardias como uma reminiscência de ritos que vêm das necrópoles de incineração préromanas da meseta espanhola (Lucas Pelliceret «//1982:238-240). Collis refere uma incineração da necrópole de Owslebury (Winchester), que atribui ao séc. IV (1977: 27). Foi igualmente atribuída a este século uma incineração aparecida em Tournai (Brulet 1980: 56).

Em Portugal não estão publicados muitos dados sobre incinerações tardias. Santo André (Viegas et olii 1981:128) e Braga (Delgado 1984:183) 
são necrópoles ou sepulturas do séc. IL De antigas escavações em outros locais, conhecem-se os materiais, que muitas vezes não se conseguem relacionar, nem com as estruturas tumulares em que foram encontrados, nem com os rituais de enterramento. É isto, aliás, o que acontece com grande parte dos enterramentos escavados na região de Eivas.

J. Nolen, ao estudar a cerâmica comum destas necrópoles, relacionou-a com outros vidros e lucernas já publicados e conseguiu reconstituir e datar alguns conjuntos de oferendas pertencentes a diversas sepulturas (1985: 141-158). Assim, em Torre das Arcas, o enterramento 38, uma incineração, é datado de fins do séc. II-séc. III (Viana e Deus 1955:250-252 e Nolen 1985: 152). No Carvalhal, uma necrópole de incineração, há igualmente enterramentos datados do séc. III (Dias 1985: 71).

Na Lage do Ouro há também incinerações tardias. Na sepultura L 37.2 apareceu um prato em cerâmica comum, imitação da forma Dragendorff 15/17 tardia. A sigillata hispânica desta forma foi datada, em Conimbriga, de fins do séc. III — séc. IV (Mayet 1975: 184). J. Nolen considera que as imitações em cerâmica comum vão do séc. II ao séc. IV (1985: 242). Este enterramento o L 32.2(6), em que apareceu um denário de Júlia Mameia, e o L 37.3, com um sestércio de Júlia Domna, são exemplos da cronologia das incinerações desta necrópole.

$\mathrm{Na}$ época romana, um outro rito funerário existente, a par da incineração, era a inumação.

A partir do séc. II d. C., as populações romanizadas começam a utilizar mais a inumação, em detrimento da incineração. Isto deve-se, por um lado, a questões religiosas. Tem-se pensado que a divulgação do Cristianismo foi o único factor responsável pela mudança de rito. No entanto, a introdução em Roma dos cultos orientais de Cibele, Isis e Mitra, que tal como o Cristianismo mostravam um maior respeito pelo corpo do morto, influenciou também o incremento da inumação como prática funerária corrente (MacDonald 1977: 37).

Por outro lado, razões de carácter económico, relacionadas com as despesas que uma incineração acarretava, poderão ter também levado a que se preferisse a inumação (Van Doorselaer 1967: 43-44).

$\mathrm{Na}$ Lage do Ouro, as sepulturas que foram referidas como sendo de forma rectangular e profundas, poderão estar associadas a rituais de inumação.

(6) Escavado em 1982. 
Em algumas localizaram-se os pregos das caixas de madeira, à semelhança das necrópoles de Tournai (Brulet 1980:57) e de San Miguel del Arroyo (Paiol 1969: Figs. 3 e 4), entre outras. O espólio apareceu encostado às paredes ou agrupado na parte sul das sepulturas (Est. 7), deixando em algumas espaço para a deposição de um corpo. No entanto, em nenhuma das sepulturas foram encontrados vestígios do esqueleto. $\mathrm{O}$ solo (granito em desagregação), poderá ter tido alguma acção sobre os ossos, levando ao seu desaparecimento. Só após análises químicas do terreno se poderá afirmar se estas sepulturas são ou não de inumação.

As sepulturas deste grupo poderão datar dos sécs. Ili e IV. Esta cronologia é-nos sugerida pelas peças de sigillata hispânica tardia, pelos instrumentos de ferro, que formam conjuntos algo comparáveis aos das necrópoles do DouroQ, e por algumas moedas.

As lucernas também parecem confirmar esta datação. A lucerna da sepultura G 37.2, com o disco liso e pequeno e a orla decorada com fiadas de pequenas pérolas (Est. 8), integra-se no tipo Dressel-Lamboglia $30 \mathrm{~B}$, datado de fins do séc. III, inícios do séc. IV (Belchior 1969:67-68). Bailey classifica-as no seu tipo R e dá-lhes uma cronologia mais lata: desde fins do séc. II aos inícios do séc. V (1980: 378-379).

Os resultados desta campanha de escavações, realizada em 1988, foram extremamente importantes para um melhor conhecimento da estação.

Em primeiro lugar, as sepulturas estavam, na sua maioria, intactas, ao contrário das escavadas em anos anteriores. Isto permitiu que se pudessem definir melhor os rituais utilizados, os conjuntos de oferendas fúnebres, a sua colocação na sepultura e a própria construção dos túmulos.

A maior quantidade de materiais datáveis encontrados veio precisar melhor e alargar a cronologia da necrópole. Com base neste espólio, pode-se dizer que os enterramentos vão pelo menos desde meados do séc. II até ao séc. IV. Obviamente que um estudo mais completo dos materiais irá contribuir para uma melhor definição da cronologia dos enterramentos, ao mesmo tempo que permitirá precisar as datações propostas para a cerâmica de época romana encontrada na região.

${ }^{7}$ ) Confrontar Caballero Zoreda 1974, onde é feito um estudo detalhado de alguns conjuntos de ferramentas provenientes destas necrópoles. 
A distribuição espacial das sepulturas veio mostrar que não há separação aparente entre os seus diversos tipos: as incinerações estão lado a lado com as possíveis inumações, fazendo supor que rituais funerários diferentes eram utilizados ao mesmo tempo.

\section{BIBLIOGRAFIA}

Bailey, D. M. (1980), A Catalogue of the Lamps in the British Museum. II. Roman Lamps made in Italy, Londres.

BALIL, A. (1966), Materiales para un indice de marcas de ceramistas en lucernas de fabricación hispánica, "Pyrenae", 2, p. 117-123.

Belchion, e. (1969), Lucernas Romanas de Conimbriga, Museu Monográfico de Conímbriga.

Bellino, A. (1900), Archeologia Christã, Lisboa.

BÉRARD, G. (1961), La nécropole gallo-romaine de La Calada à Cabasse (Var), "Gallia", 19, p. 105-158.

Brulet, R. (1980), Tournai. F ouille d'une nécropole du Bas-Empire, "Archeologia”, 141, Agosto.

Caballero Zoreda, L. (1974), La necrópolis tardorromana de Fuentespreadas (Zamora). Un asentamiento en el Valle del Duero, "Excavaciones Arqueológicas en España”, 80.

Cabral, M. E. F. (1974-1977), Lucernas romanas de Alcácer do Sal, "O Arqueólogo Português", III Série, 7-9, p. 347-354.

Carvalho, R. (1987), Urna forja romana em Vale de Junco, "Arqueologia no Vale do Tejo. Catálogo da exposição", Lisboa, p. 64-65.

Coolis, J. (1977), Owslebury (Hants) and the problems of burials on rural settlements, in REECE, R.(ed.) "Burial in the Roman World", CBA Research Report, 22, p. 26-34.

Delgado, M. (1984), Sepultura romana encontrada junto ao Largo Carlos AmaranteBraga, "Lvcerna. Homenagem a D. Domingos de Pinho Brandão", p. 179-202 .

DE KuJu, H. (1987), Un ensemble à incineration tardif à Briord (Ain), "Nécropoles à incinération du Haut-Empire", Lyon, p. 141-142.

Dias, L. F. (1985), A necrópole romana do Carvalhal, "Informação Arqueológica", 7, p. $70-71$. 
EnCARnaÇão, José d' (1984), Inscrições romanas do Conventus Pacensis, Coimbra (=IRCP).

Frade, Helena e CAetano, José Carlos (1985), A necrópole romana da Lage do Ouro. Primeiros resultados. "las Jornadas de Arqueologia do Nordeste AlentejanoActas. Castelo de Vide”, p. 133-143.

GuÉRY, R. (1985),La nécropole orientale deSitifis (Sétif Algérie). Fouilles de 19661967. "Études d' Antiquités Africaines", CNRS, Paris.

Lucas Pellicer, M. R., Alonso Sanchez, $M$ - A., Blasco Bosqued, M. C., Fernandez OchoA, M. C., Rubio De Miguel, I. L. (1982), Necrópolis romana de La Torrecilla (Getafe, Madrid), "Noticiario Arqueológico Hispanico", 13, p. 214-245.

Macdonald, J. Pagan religions and burialpractics, in REECE, R.(ed.), "Burial in the Roman World", CBA Research Report, 22, p. 35-38.

MaYet, F. (1975), Les sigillées hispaniques, Fouilles de Conimbriga. TV. Les sigillées, Paris.

Nolen, J. U. S. (1985), Cerâmica comum de necrópoles do Alto Alentejo, Lisboa.

Palol, P. de (1958), Las excavaciones de San Miguel del Arroyo. Un conjunto de necrópolis tardorromanas en el Valle del Duero, "Boletín del Seminario de Estudios de Arte y Arqueologia”, 24, p. 209-217.

PONTE, S. (1986), Algumas peças metálicas de necrópoles romanas dos distritos de Portalegre e Évora, "Conimbriga", 25, p. 99-129.

Simões, M. H. (1985), Vidros romanos do Museu do Crato, "1-s Jornadas de Arqueologia do Nordeste Alentejano-Actas. Castelo de Vide", p. 123-125

VAN DoORselaer, A. (1967), Les nécropoles d'époque romaine en Gaule Septentrionale, Brugge.

Viana, A. e Deus, A. D. (1955), Necrópolis de la Torre das Arcas, “Archivo Español de Arqueologia", 28, p. 244-265.

ViEGAS, J. R., Nolen, J. U. S. e Dias, M. L. F. (1981), A necrópole de Santo André, "Conimbriga", 20, p. 5-180. 


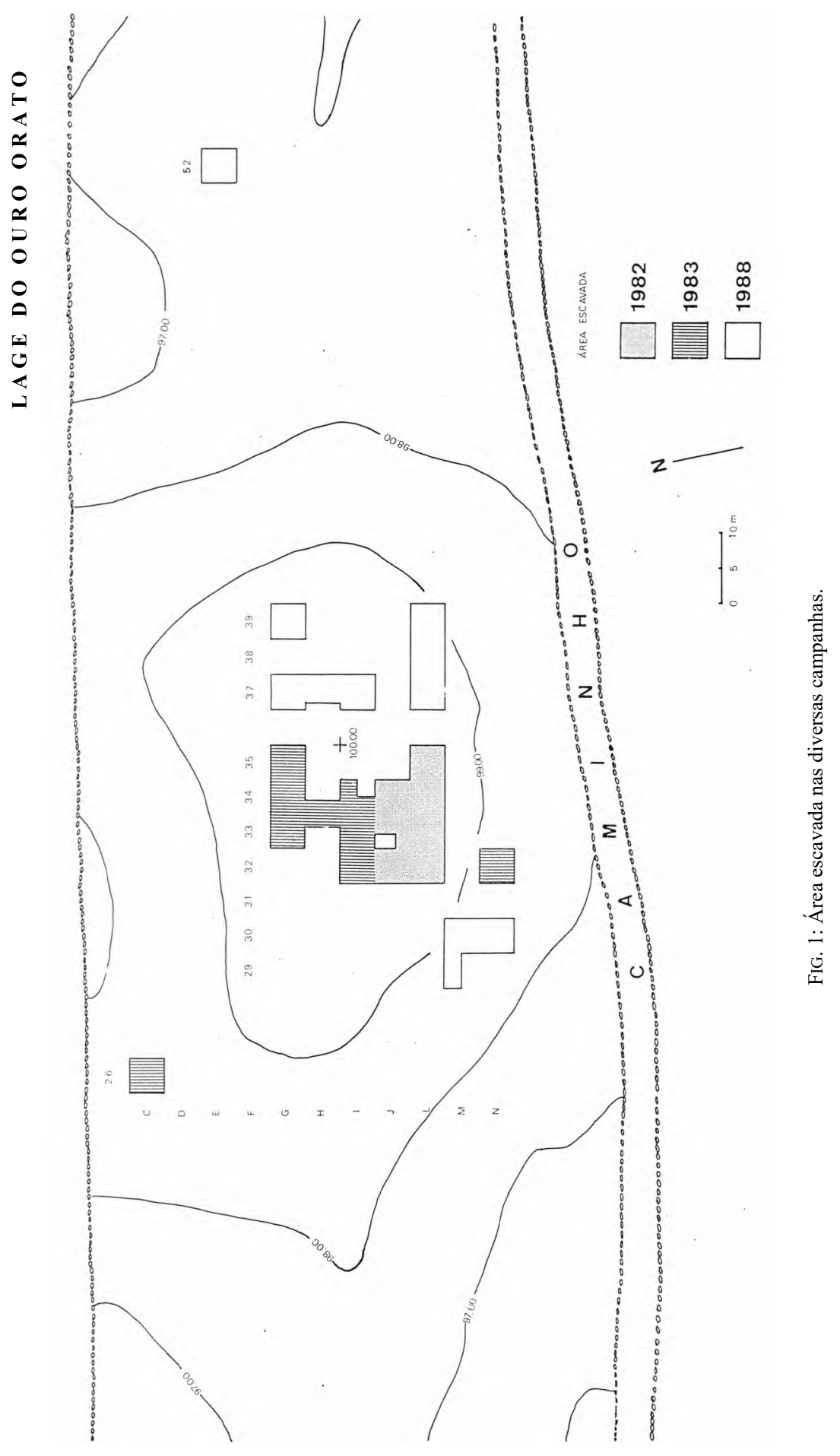



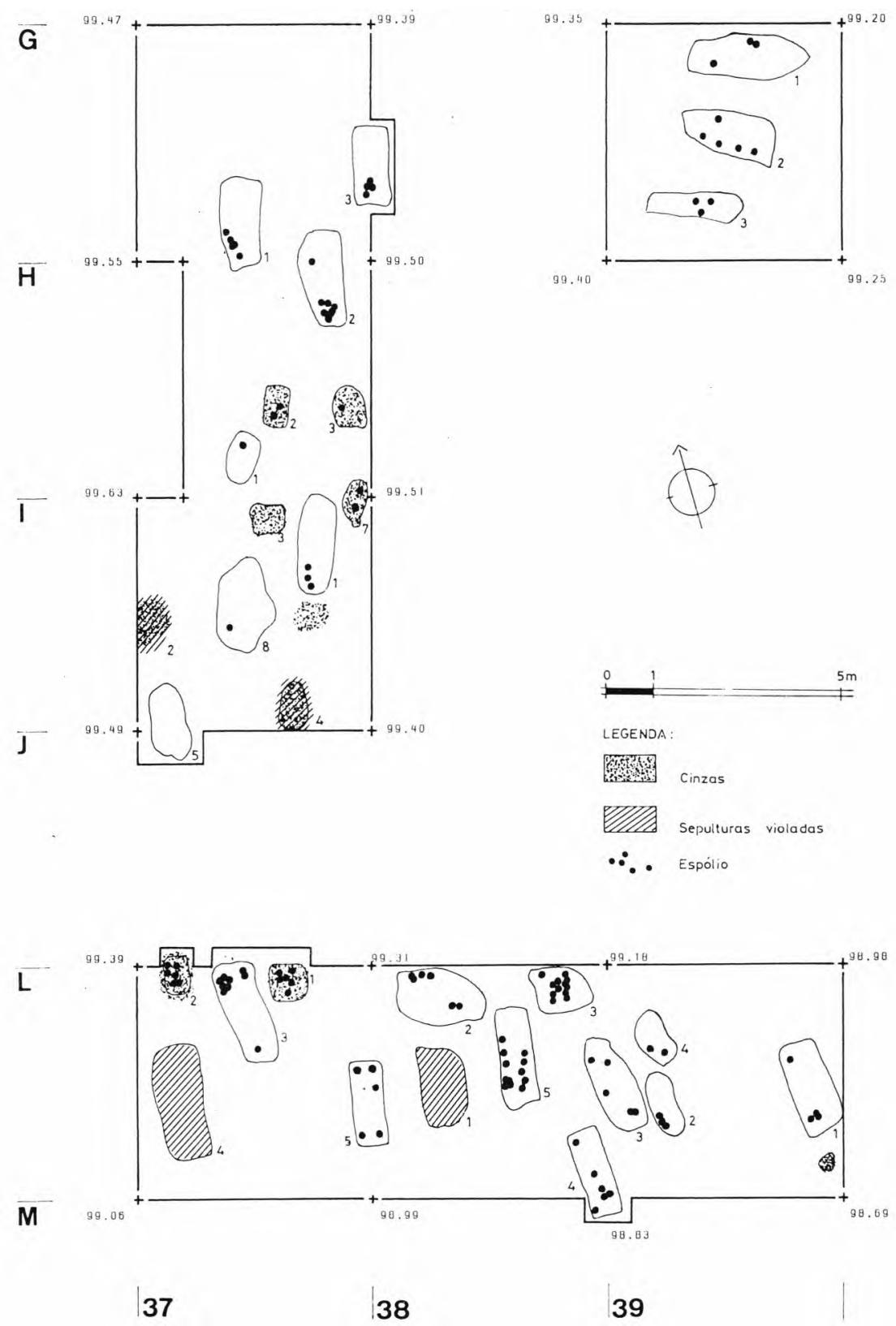

FIG. 2: Planta parcial da campanha de 1988. 


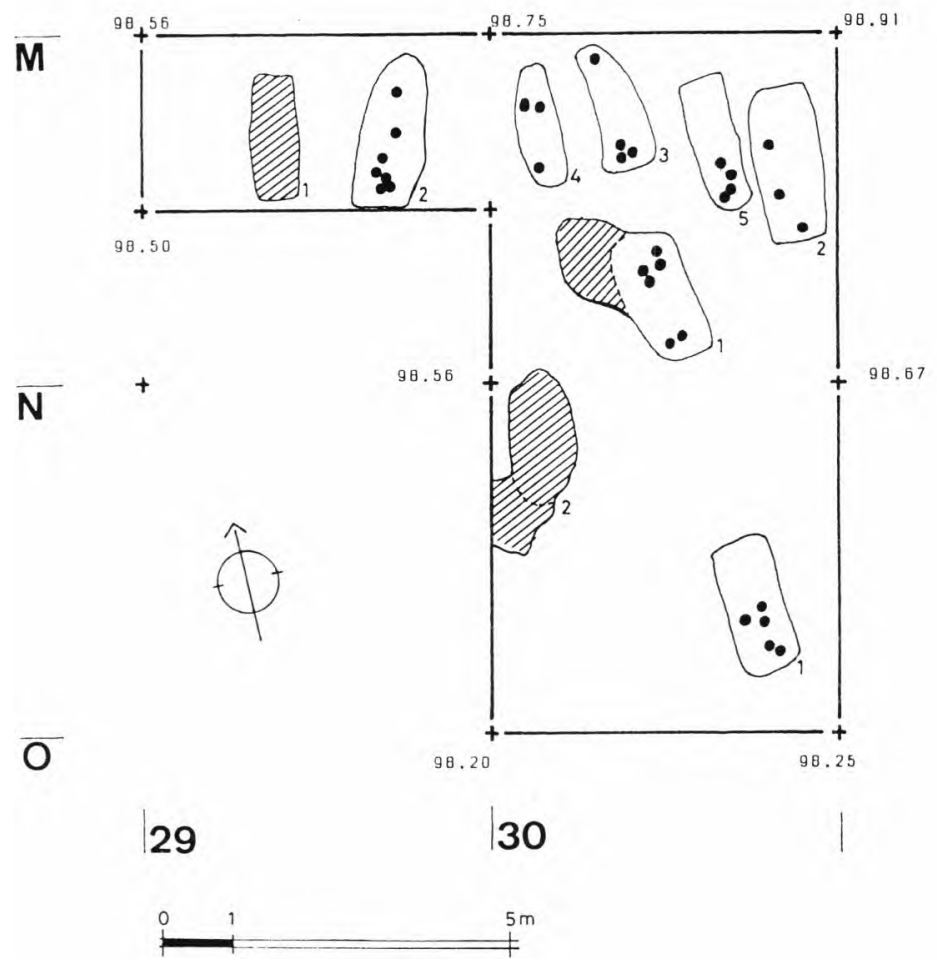

FIG. 3: Planta parcial da campanha de 1988. 


\section{EST. I}

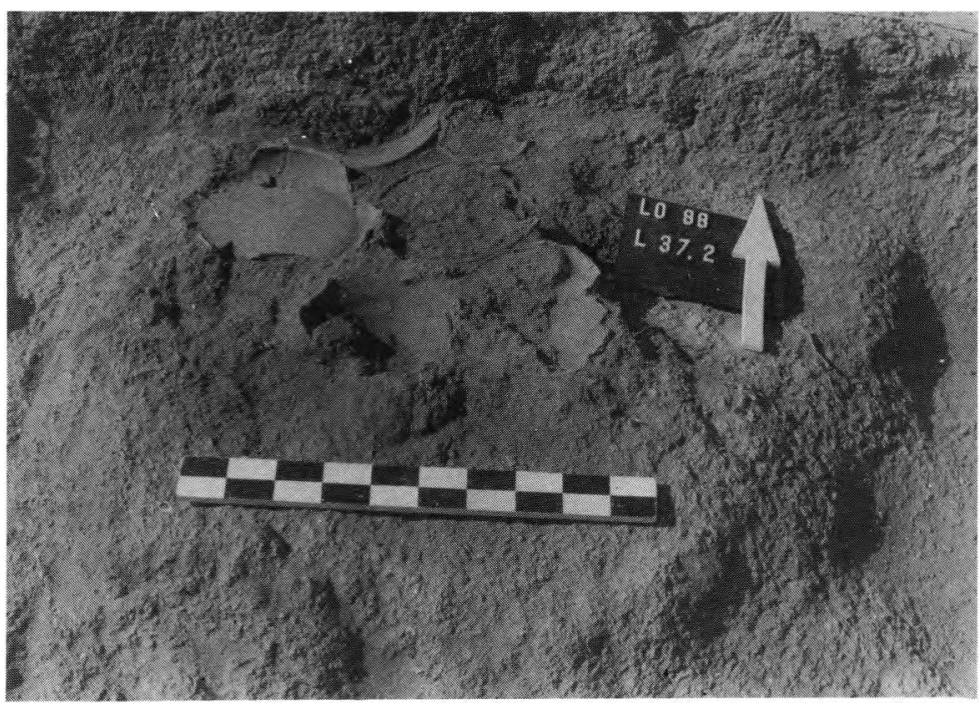

Sepultura L 37.2 em fase de escavação. 
EST. II

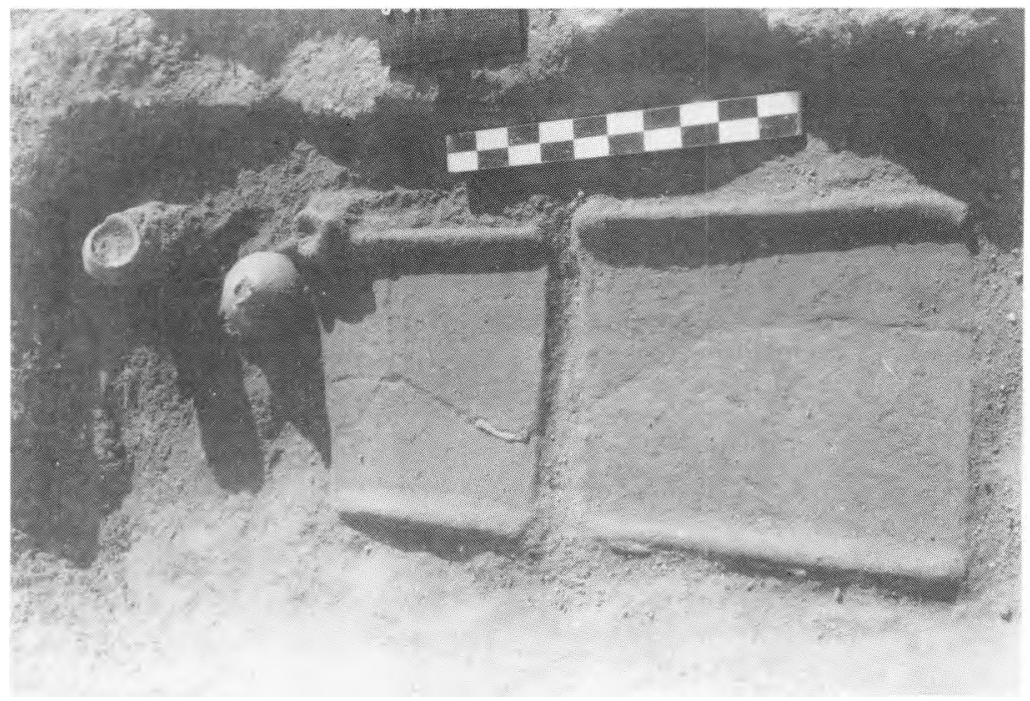

Revestimento do fundo da sepultura G. 37.3 
EST. III

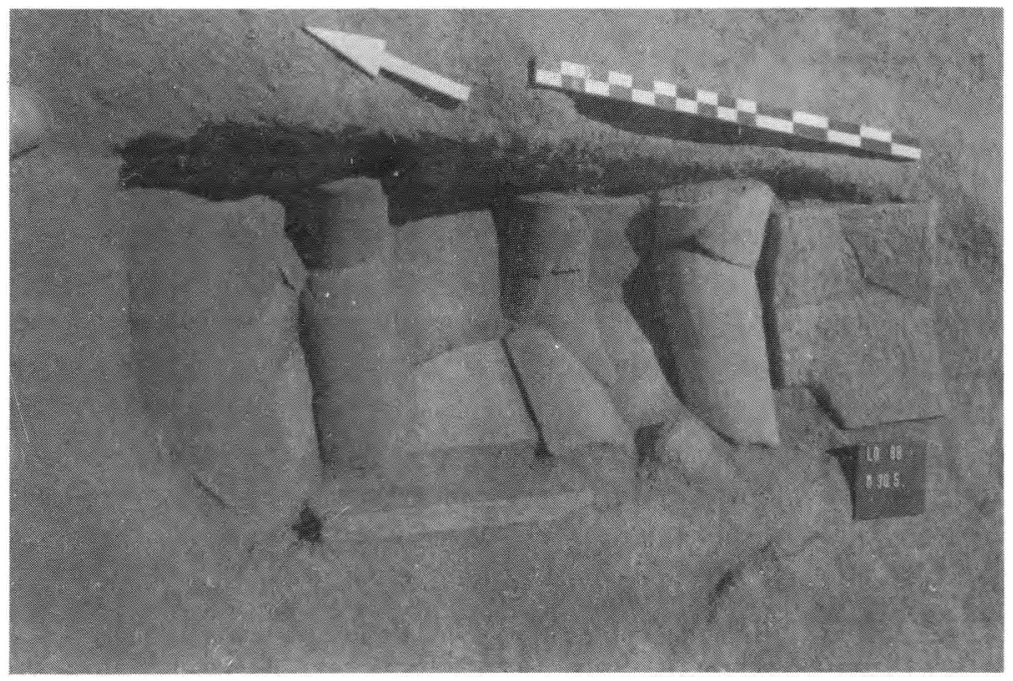

Telhado da sepultura M 30.5 
EST. IV

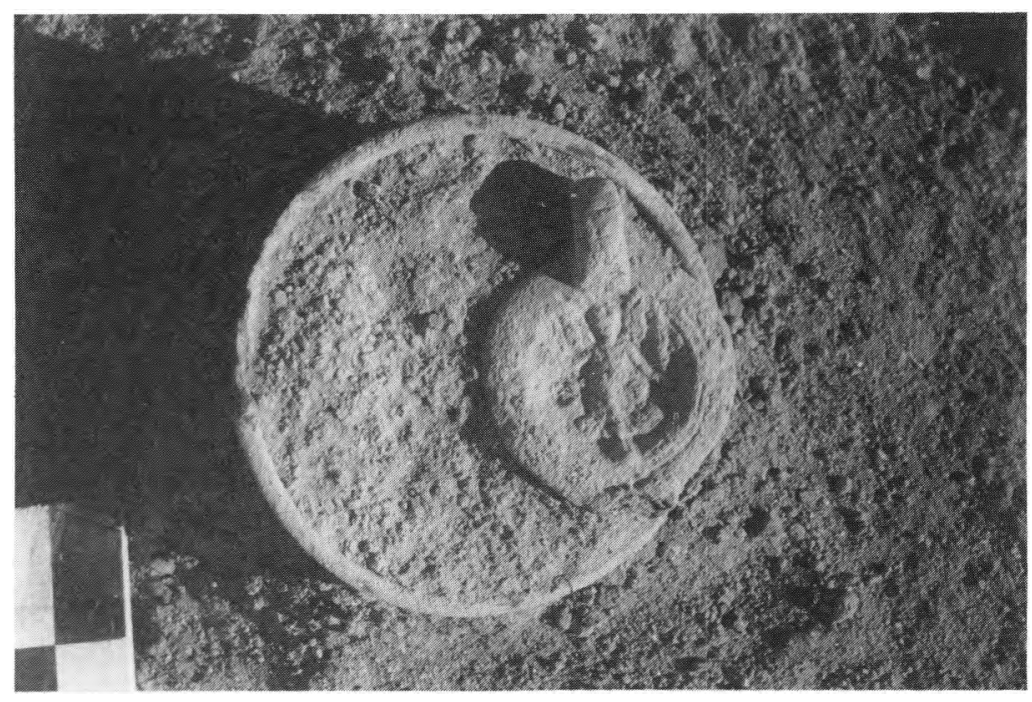

Lucerna, marcada GES, da sepultura L 39.3. 
EST.V

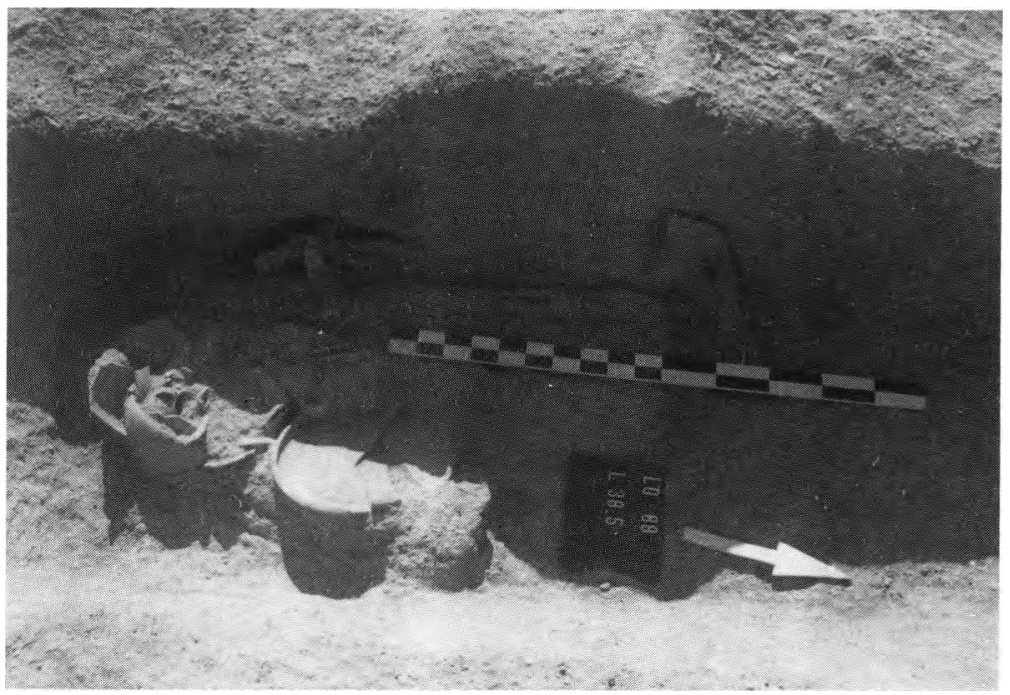

Sepultura L 38.5 com o espólio. 
Est. VI

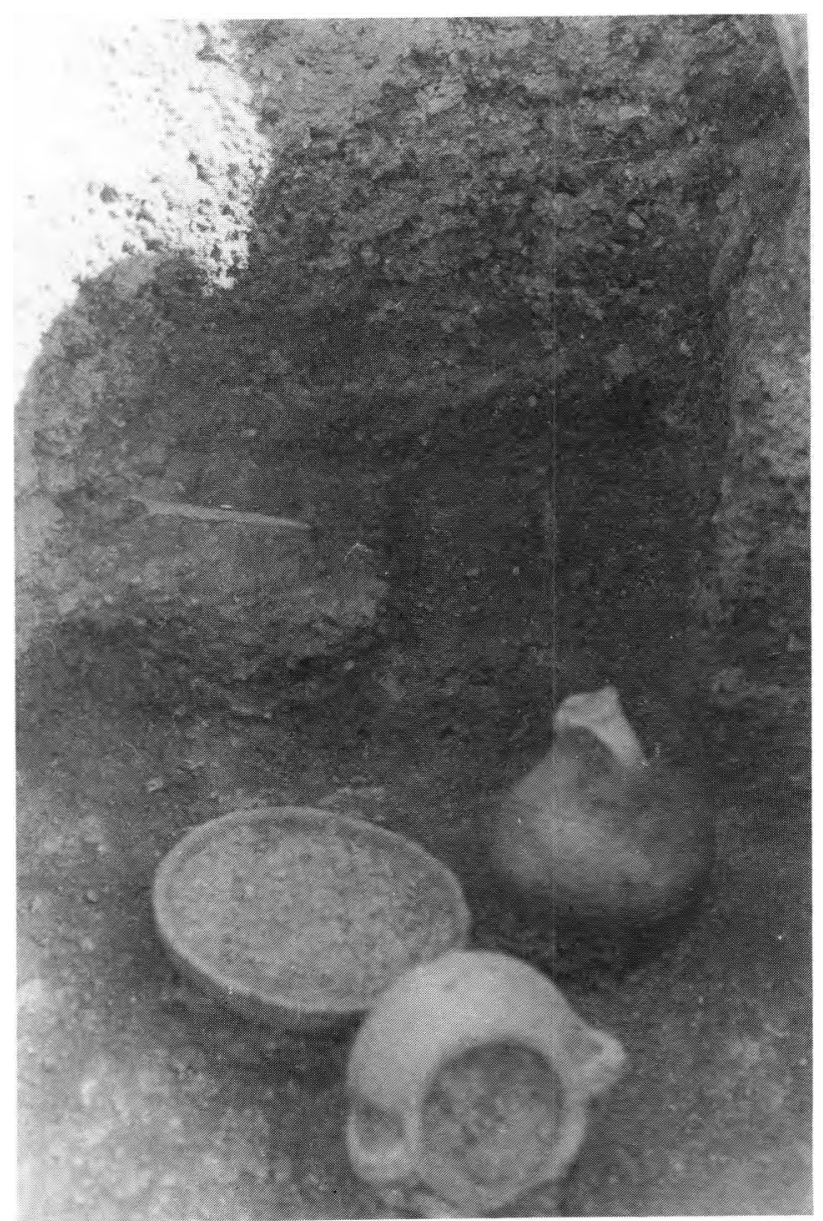

Pormenor dos pregos da sepultura L 38.4. 
EST. VII

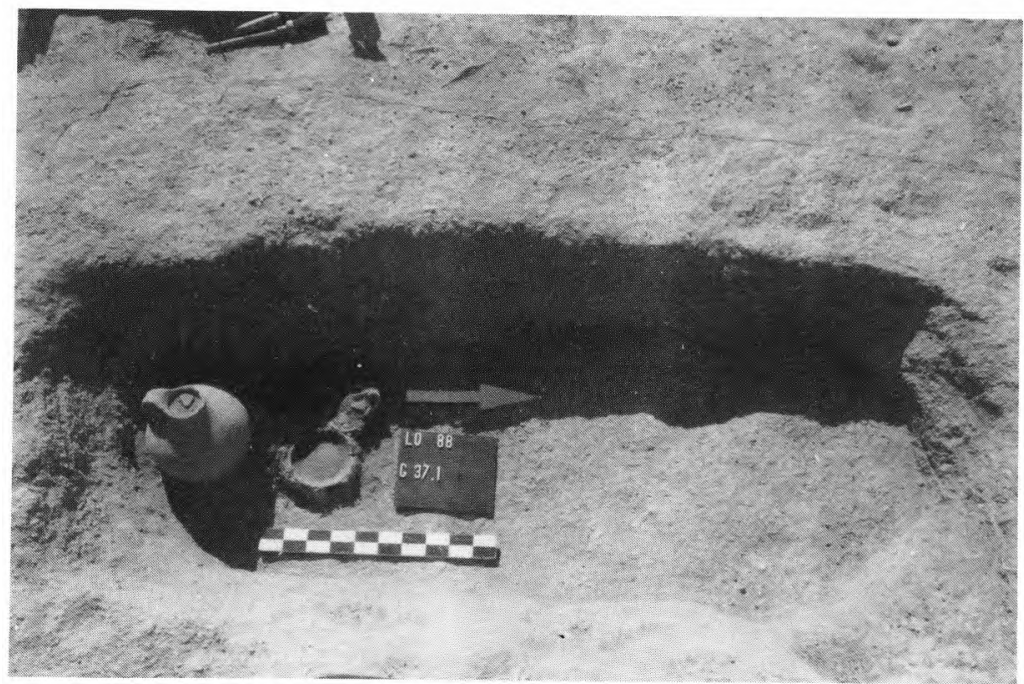

Arrumação do espólio na sepultura G 37.1 
Est.VIII

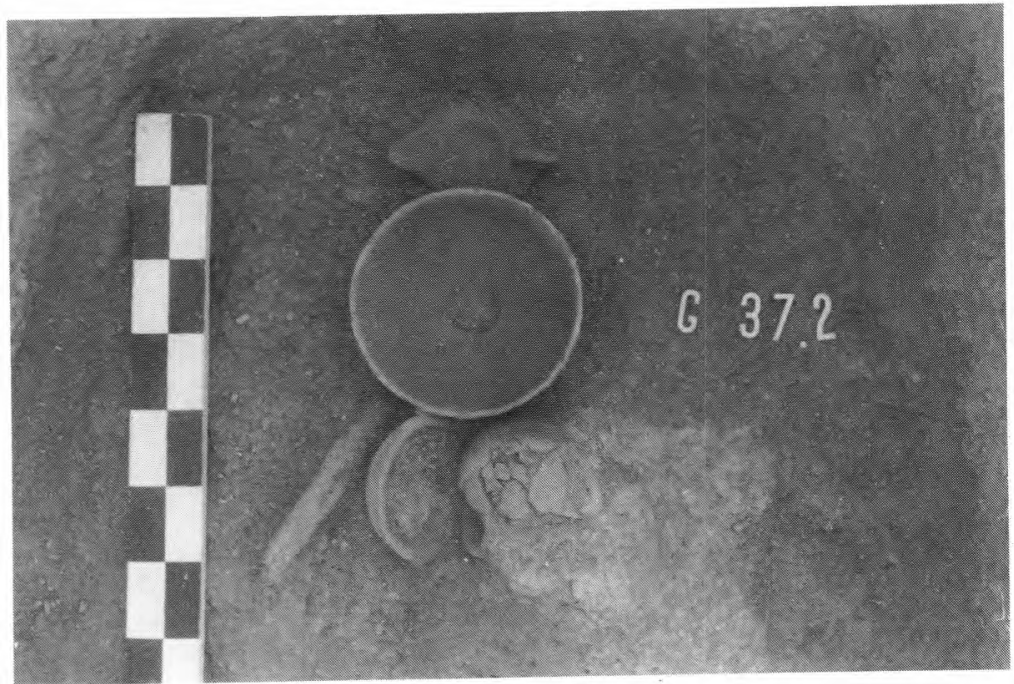

Parte do espólio, incluindo a lucerna, da sepultura G 37.2 